\title{
Efecto de las microondas sobre la concentración de la caseína en la leche de vaca
}

\author{
Karla del Rocío Mejía Fustamante y Blanca M. Romero Guzmán \\ Universidad Nacional Pedro Ruiz Gallo, Calle Juan XXIII, Lambayeque, Perú \\ Recibido del 12 de octubre del 2018. Revisado el 3 de diciembre del 2018. \\ Aceptado el 5 de diciembre del 2018
}

DOI: https://doi.org/10.33017/RevECIPeru2018.0012/

\section{Resumen}

La presente investigación tiene como objetivo determinar el efecto de las microondas sobre la concentración de la caseína en la leche de vaca para lo cual se utilizó de manera preliminar un ensayo de estabilidad proteica, luego un reconocimiento de proteínas por el método de Biuret y posteriormente una cuantificación de proteínas a $25^{\circ} \mathrm{C}$ por el método Sorensen obteniendo1,17 g de caseína (2,065 \%). Se tomaron cinco muestras de leche de $10 \mathrm{ml}$ cada una para ser sometido al microondas con tiempos de exposición de $10 \mathrm{~s}, 20 \mathrm{~s}, 30 \mathrm{~s}, 60 \mathrm{~s}$ y 120 s. Midiendo la temperatura al término de los mismos, las cuales Fueron de $29^{\circ} \mathrm{C}, 35^{\circ} \mathrm{C}, 44^{\circ} \mathrm{C}, 52^{\circ} \mathrm{C}$ y $77^{\circ} \mathrm{C}$. Al finalizar la exposición de la leche al microondas, se tomó tres alícuotas de diez mililitros de cada una de las muestras para determinar el porcentaje y cantidad de caseína total utilizando el método de Sorensen-Walker seguido de un aislamiento de caseína mediante una valoración ácido-base y adición de ácido acético $1 \mathrm{M}$, concluyendo que la concentración de caseína total en la leche de vaca se ve afectada con el aumento temperatura dentro del microondas, de una concentración de 2,065 \% a 0,761 \% de caseína, afectando su valor nutricional.

Descriptores: Caseína, microondas, leche.

\section{Abstract}

The objective of this research is to determine the effect of microwaves on the concentration of casein in cow's milk for which it was used in a preliminary way a protein stability test, then a protein recognition by the method of Biuret and subsequently a quantification of proteins at $25^{\circ} \mathrm{C}$ by the Sorensen method obtaining $1,17 \mathrm{~g}$ of casein $(2.065 \%)$. Five samples of milk of $10 \mathrm{ml}$ were taken each to be subjected to the microwave with exposure times of $10 \mathrm{~s}, 20 \mathrm{~s}, 30 \mathrm{~s}, 60 \mathrm{~s}$ and $120 \mathrm{~s}$. Measuring the temperature at the end of them, which They were 29 ${ }^{\circ} \mathrm{C}, 35^{\circ} \mathrm{C}, 44^{\circ} \mathrm{C}, 52^{\circ} \mathrm{C}$ and $77^{\circ} \mathrm{C}$. At the end of the exposure of the milk to the microwave, three aliquots of ten millilitres were taken of each of the samples to determine the percentage and amount of total casein using the Sorensen-Walker method followed by a casein isolation using an acid-base titration and addition of $1 \mathrm{M}$ acetic acid, concluding that the Total casein concentration in cow's milk is affected with the increase temperature inside the microwave, from a concentration of $2.065 \%$ to $0.761 \%$ of casein, affecting its nutritional value.

Keywords: Casein, microwave, milk.

\section{Introducción}

La sociedad en la actualidad busca reducir el tiempo en sus quehaceres diarios, lo cual hace de su vida cada vez más agitada. Las mujeres modernas se encuentran con el inconveniente de tener que cumplir con el horario de trabajo y su rol de madre sobre todo aquella que tiene lactantes o niños con edad preescolar y utiliza leche de vaca para su alimentación, la cual le obliga a guardarla en la refrigeradora para posteriormente calentarla en el microondas por su rapidez, desconociendo los 
efectos sobre la calidad de la leche. Diversas investigaciones, han confirmado los riesgos que significan la radiación de microondas sobre la leche cruda, dado a que las grasas, proteínas, sustancias secas y las concentraciones de lactosa disminuyen en función del tiempo de exposición en microondas [1]; las concentraciones de grasa, proteína y lactosa disminuyen durante la exposición de leche en el microondas, especialmente a 120 segundos, constituyendo un riesgo como alimento [2].

Se plantea la hipótesis de que la concentración de la caseína disminuye con el tiempo de exposición en el microondas. El objetivo general de este trabajo de investigación es determinar el efecto del microondas sobre la concentración de la caseína en la leche de vaca a diferentes tiempos de exposición. Los objetivos específicos que nos hemos planteados son los siguientes:

1. Determinar la estabilidad proteica de la leche de vaca que va a ser sometida al microondas.

2. Determinar el contenido de proteínas totales y caseína de la leche de vaca a temperatura ambiente.

3. Determinar el contenido de proteínas totales y caseína de la leche de vaca en el microondas variando el tiempo de exposición y midiendo la temperatura alcanzada.

\section{Metodología}

La leche de vaca fue adquirida en el mercado de la ciudad de Lambayeque, puesto $\mathrm{N}^{\circ} 2$, tomando como muestra representativa 1 litro.

\subsection{Estabilidad proteica}

En un tubo de ensayo se colocó una alícuota de 2 mililitros de leche y 2 mililitros de etanol de $70^{\circ}$, se tapó el tubo y se mezcló suavemente los líquidos invirtiendo el tubo de dos a tres veces, sin agitación. Luego se inclinó el tubo en varias direcciones y se observó a contraluz si ha ocurrido o coagulación de la mezcla. Si la leche ha sufrido acidificación o es anormal por contener calostro o provenir de vacas afectadas con mastitis, se forman coágulos y el ensayo se reporta como positivo, indicando la inestabilidad de la leche $[3,4]$.

\subsection{Reconocimiento de proteínas -Método cualitativo de Biuret}

Se tomó en un vaso precipitado una alícuota de 5 mililitros de leche de vaca y se adicionó 2 mililitros de reactivo de Biuret gota a gota con agitación constante hasta que apareció un color violeta.

\subsection{Cuantificación de proteínas -Método de Sorensen}

Se tomó una alícuota de 10 mililitros de leche problema y colocada en un matraz Erlenmeyer, al cual se añadió 20 mililitros de agua destilada y 3 gotas de fenolftaleína. Se neutralizó la acidez titulable natural de la leche con solución de hidróxido de sodio $0.1 \mathrm{~N}$ hasta la aparición de un color rosa (gasto1). Posteriormente se adicionó a la leche neutralizada 2 mililitros de formol para dejar libres los grupos carboxilos de los aminoácidos. Tras la adición del formol la muestra se acidifica tornándose nuevamente a color blanco, luego se añadió 3 gotas de fenolftaleína y se valoró la acidez con hidróxido sódico, hasta la aparición del color rosa (gasto2).

$$
\begin{aligned}
\% \text { proteínas totales } & =\text { gasto }_{2} \times 2,24 \\
\% \text { caseína total } & =\text { gasto }_{2} \times 1,63
\end{aligned}
$$

\subsection{Aislamiento de caseína}

Se calentó en un vaso de precipitado $150 \mathrm{ml}$ de agua destilada a $38^{\circ} \mathrm{C}$, luego se añadió una alícuota de $50 \mathrm{ml}$ de leche problema y se adicionó ácido acético $1 \mathrm{M}$ gota a gota con agitación constante hasta la formación de un precipitado blanco (leche cortada). A continuación, se centrifugó y se lavó el precipitado con 20 mililitros de etanol y 10 mililitros de éter etílico. Nuevamente se procedió a centrifugar y se desechó el líquido quedando un precipitado blanco de fácil manipulación que es la caseína, se deja secar y se procede a pesar.

\section{Resultados}

\subsection{Estabilidad proteica}

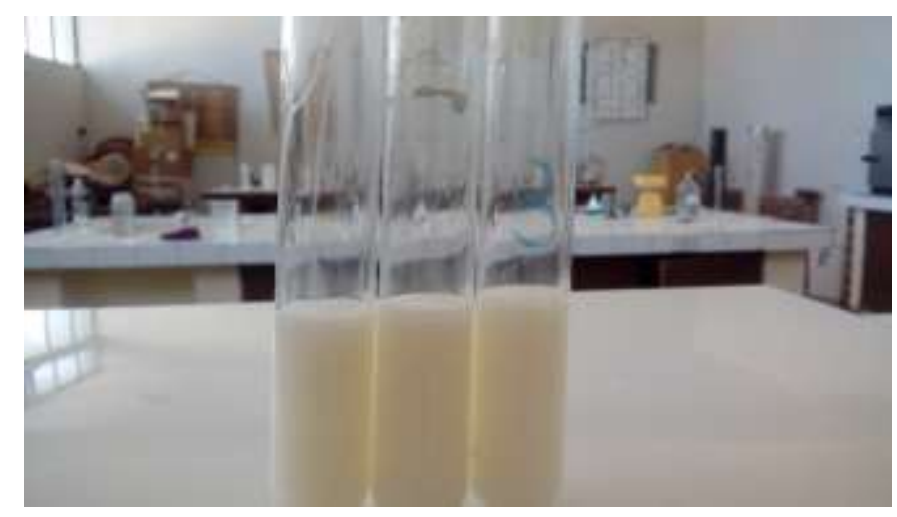

Figura 1: Leche sin Presencia de coágulos (-). 
Tabla 1: Prueba de la Estabilidad Proteica de la leche a $25^{\circ} \mathrm{C}$.

\begin{tabular}{|c|c|c|c|}
\hline Muestra & $\begin{array}{l}\text { Vol. de } \\
\text { Alcohol } \\
(\mathrm{ml})\end{array}$ & $\begin{array}{l}\text { Vol. de } \\
\text { Leche }(\mathrm{ml})\end{array}$ & Resultado \\
\hline 1 & 2 & 2 & Negativo \\
\hline 2 & 2 & 2 & Negativo \\
\hline 3 & 2 & 2 & Negativo \\
\hline
\end{tabular}

\subsection{Reconocimiento de proteínas}

Por el método cualitativo de Biuret, una coloración violeta indica resultado positivo para proteína.

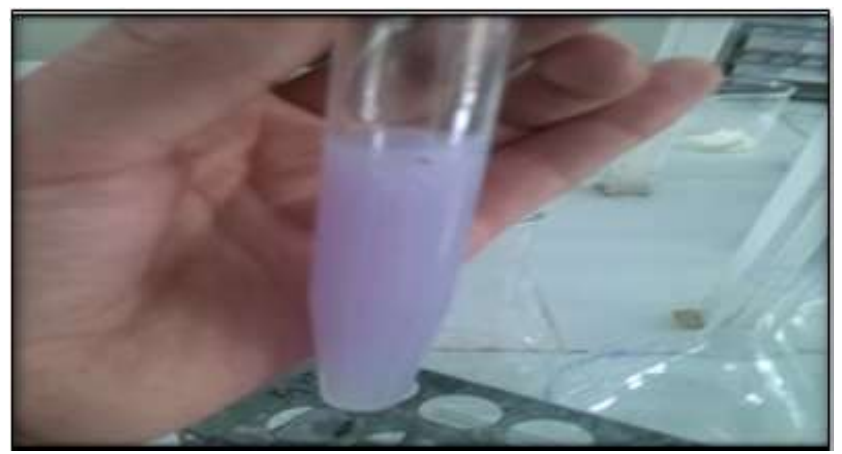

Figura 2: Aparición de la coloración violeta (+).

\subsection{De la cuantificación de proteínas}

Mediante el método de Sorensen, a temperatura ambiente (25) y posteriormente sometido la microondas.

Tabla 2: Análisis de la leche de vaca a Temperatura ambiente $\left(25^{\circ} \mathrm{C}\right)$.

\begin{tabular}{|c|c|c|c|c|}
\hline Muestra & $\begin{array}{c}\text { Acidez } \\
(\%)\end{array}$ & $\begin{array}{c}\text { Proteínas } \\
\text { totales } \\
(\%)\end{array}$ & $\begin{array}{c}\text { Caseína } \\
\text { total }(\mathrm{g})\end{array}$ & $\begin{array}{c}\text { Caseína } \\
\text { total }(\%)\end{array}$ \\
\hline 1 & 0,190 & 2,688 & & 1,956 \\
\hline 2 & 0,190 & 2,912 & & 2,119 \\
\hline 3 & 0,180 & 2,912 & & 2,119 \\
\hline $\mathrm{X}$ & 0,187 & 2,837 & 1,170 & 2,065 \\
\hline$\sigma^{2}$ & $\begin{array}{c}3,333 \times \\
10^{-5}\end{array}$ & $\begin{array}{c}0,016725 \\
33\end{array}$ & & 0,00885 \\
& \multicolumn{3}{|c|}{} \\
\hline
\end{tabular}

Tabla 3: Análisis de la leche de vaca a diferentes tiempos de exposición al microondas.

\begin{tabular}{|c|c|c|c|c|}
\hline \multicolumn{5}{|c|}{$\begin{array}{l}\text { Tiempo de Exposición: } 10 \text { s y Temperatura } \\
\text { alcanzada: } 29^{\circ} \mathrm{C} \text {. }\end{array}$} \\
\hline Muestra & $\begin{array}{l}\text { Acidez } \\
(\%)\end{array}$ & $\begin{array}{l}\text { Proteínas } \\
\text { totales (\%) }\end{array}$ & $\begin{array}{l}\text { Caseína } \\
\text { total (g) }\end{array}$ & $\begin{array}{l}\text { Caseína total } \\
(\%)\end{array}$ \\
\hline 1 & 0,160 & 2,240 & & 1,630 \\
\hline 2 & 0,160 & 2,240 & & 1,630 \\
\hline 3 & 0,150 & 2,016 & & 1,467 \\
\hline $\bar{X}$ & 0,157 & 2,165 & 0,98 & 1,576 \\
\hline$\sigma^{2}$ & $\begin{array}{c}3,333 \times \\
10^{-5}\end{array}$ & 0,01672533 & & 0,00885633 \\
\hline \multicolumn{5}{|c|}{$\begin{array}{l}\text { Tiempo de Exposición: } 20 \text { s y Temperatura } \\
\text { alcanzada: } 35^{\circ} \mathrm{C} \text {. }\end{array}$} \\
\hline Muestra & $\begin{array}{l}\text { Acidez } \\
(\%)\end{array}$ & $\begin{array}{l}\text { Proteínas } \\
\text { totales }(\%)\end{array}$ & $\begin{array}{l}\text { Caseína } \\
\text { total (q) }\end{array}$ & $\begin{array}{l}\text { Caseína total } \\
(\%)\end{array}$ \\
\hline 1 & 0,150 & 2,016 & & 1,467 \\
\hline 2 & 0,1060 & 2,016 & & 1,467 \\
\hline 3 & 0,160 & 2,016 & & 1,467 \\
\hline $\bar{x}$ & 0,157 & 2,016 & 0,96 & 1,467 \\
\hline$\sigma^{2}$ & $\begin{array}{c}3,333 \times \\
10^{-5}\end{array}$ & 0,000 & & $7.396 \times 10^{-32}$ \\
\hline \multicolumn{5}{|c|}{$\begin{array}{l}\text { Tiempo de Exposición: } 30 \text { s y Temperatura } \\
\text { alcanzada: } 44^{\circ} \mathrm{C} \text {. }\end{array}$} \\
\hline Muestra & $\begin{array}{c}\text { Acidez } \\
(\%)\end{array}$ & $\begin{array}{c}\text { Proteínas } \\
\text { totales }(\%)\end{array}$ & $\begin{array}{l}\text { Caseína } \\
\text { total }(g)\end{array}$ & $\begin{array}{c}\text { Caseína total } \\
(\%)\end{array}$ \\
\hline 1 & 0.15 & 1.792 & & 1.304 \\
\hline 2 & 0.16 & 1.792 & & 1.304 \\
\hline 3 & 0.16 & 2.016 & & 1.467 \\
\hline $\mathrm{X}$ & 0.157 & 1.867 & 0.94 & 1.358 \\
\hline$\frac{\sigma^{2}}{2}$ & $\begin{array}{c}3,333 \times \\
10^{-5} \\
\end{array}$ & 0.01672533 & & 0.00885633 \\
\hline \multicolumn{5}{|c|}{$\begin{array}{l}\text { Tiempo de Exposición: } 60 \text { s y Temperatura } \\
\text { alcanzada: } 52^{\circ} \mathrm{C} \text {. }\end{array}$} \\
\hline Muestra & $\begin{array}{c}\text { Acidez } \\
(\%)\end{array}$ & $\begin{array}{l}\text { Proteínas } \\
\text { totales (\%) }\end{array}$ & $\begin{array}{l}\text { Caseína } \\
\text { total }(g)\end{array}$ & $\begin{array}{c}\text { Caseína total } \\
(\%)\end{array}$ \\
\hline 1 & 0.16 & 1.568 & & \\
\hline 2 & 0.15 & 1.568 & & \\
\hline 3 & 0.15 & 1.792 & & \\
\hline $\mathrm{X}$ & 0.153 & 1.643 & 0.93 & \\
\hline$\overline{\sigma^{2}}$ & $\begin{array}{c}3,333 \times \\
10^{-5} \\
\end{array}$ & 0.01672533 & & 0.00885633 \\
\hline \multicolumn{5}{|c|}{$\begin{array}{l}\text { Tiempo de Exposición: } 120 \text { s y Temperatura } \\
\text { alcanzada: } 77^{\circ} \mathrm{C} \text {. }\end{array}$} \\
\hline Muestra & $\begin{array}{l}\text { Acidez } \\
(\%)\end{array}$ & $\begin{array}{l}\text { Proteínas } \\
\text { totales (\%) }\end{array}$ & $\begin{array}{l}\text { Caseína } \\
\text { total (g) }\end{array}$ & $\begin{array}{l}\text { Caseína total } \\
(\%)\end{array}$ \\
\hline 1 & 0.16 & 1.12 & & 0.815 \\
\hline 2 & 0.15 & 1.12 & & 0.815 \\
\hline 3 & 0.16 & 0.896 & & 0.652 \\
\hline$X$ & 0.15 & 1.045 & 0.60 & 0.761 \\
\hline$\sigma^{2}$ & $\begin{array}{c}3,333 \times \\
10^{-5} \\
\end{array}$ & 0.01672533 & & 0.00885633 \\
\hline
\end{tabular}




\subsection{Interpretación de los resultados}

Los resultados de la tabla 1 sobre la estabilidad proteica de la leche está acorde con lo estipulado en [3], referente a la prueba al alcohol, con resultado negativo: no coagulable.

En la tabla 2 y 3 , se puede observar la variación de los valores de la proteína total, acidez y caseína, tanto a temperatura ambiente de $25^{\circ} \mathrm{C}$ y luego a 10 segundos de exposición al microondas.

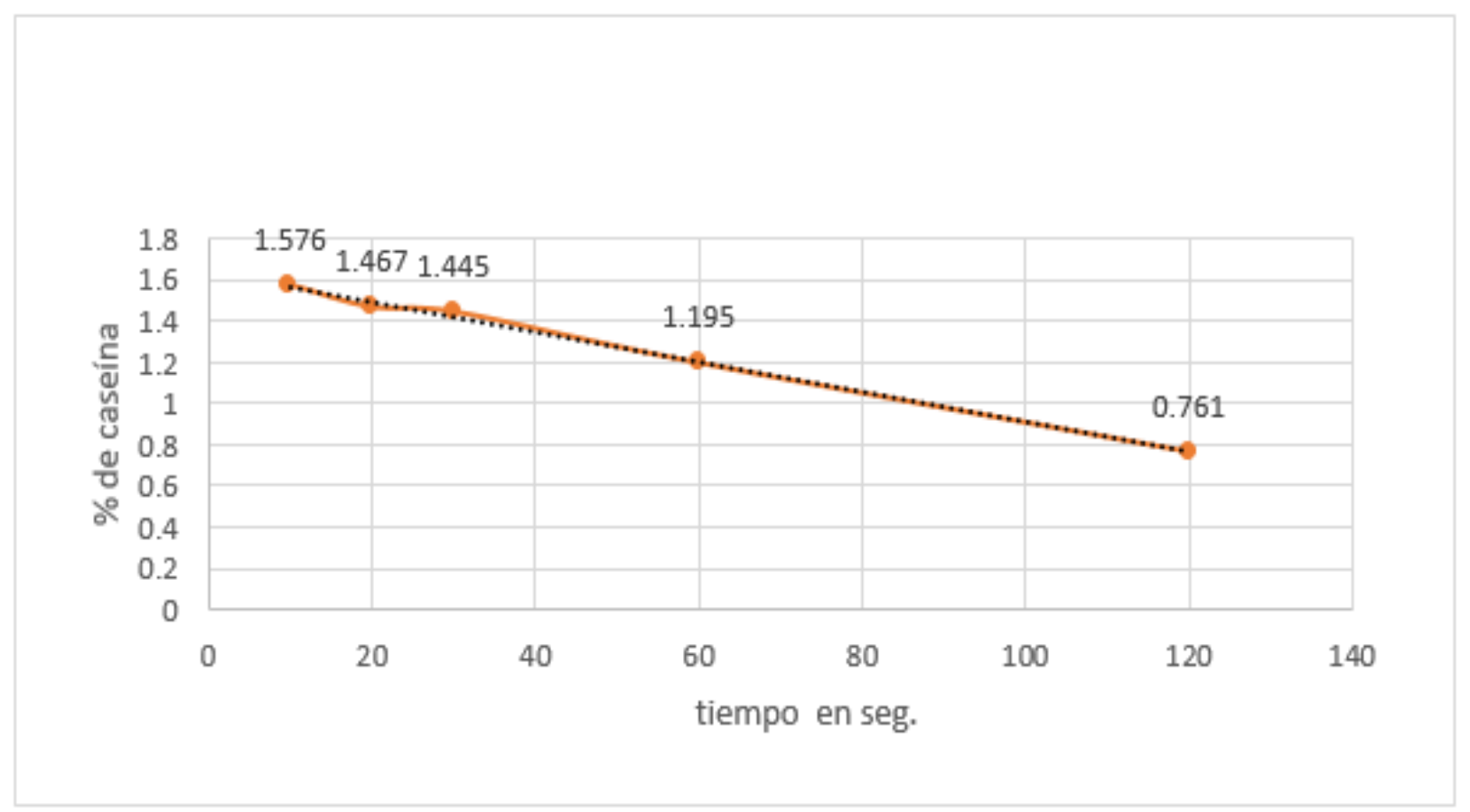

Figura 3: Tiempo de exposición de la leche de vaca al Microondas vs \% de Caseína.

Según la figura 3 el porcentaje de caseína en la leche fue disminuyendo de 1,576 a 0,761 a medida que el tiempo de exposición en el microondas fue aumentando, esto confirma que las microondas debilitan la estructura secundaria de las proteínas porque le originan un especial plegamiento, la cual es importante para la estabilidad de la caseína frente a la desnaturalización por el calor [5].

En la tabla 3, los resultados están acorde con lo referido por $[1,2]$ en el que las grasas, proteínas, sustancias secas y concentración de lactosa disminuyen a medida que el tiempo de exposición en el microondas aumenta, especialmente a $120 \mathrm{~s}$, constituyendo un riesgo como alimento.

\section{Conclusiones}

Al realizar la prueba de estabilidad proteica, el resultado fue negativo lo que indica la capacidad de la leche de resistir altas temperaturas sin presentar coagulación visible.
El contenido de caseína en la leche de vaca a temperatura ambiente $\left(25^{\circ} \mathrm{C}\right)$, fue como promedio de $1.17 \mathrm{gr}$ de caseína $(2,065 \%)$ con una varianza de 0,00885633 lo que nos indica la cercanía de los datos respecto al promedio.

A medida que aumenta el tiempo de exposición microondas de la leche de vaca, la temperatura aumenta; y la concentración de la caseína disminuyendo; a los $120 \mathrm{~s}$ alcanzo una temperatura $77^{\circ} \mathrm{C}$ y una concentración promedio de caseína de $0,60 \mathrm{~g}(0,761 \%)$ con una varianza de 0,00885633 respecto al promedio.

\section{Agradecimientos}

Los participantes de esta investigación a agradecen a la Universidad Nacional Pedro Ruiz Gallo por el apoyo brindado para su ejecución.

\section{Referencias}


[1] I. Cretescu, R. Caprita, S. Ropciuc, and O. Munteanu, Romanian Reports in Physics 67 (2015) 423- 430.

[2] J. Gille, Aseguramiento de la calidad sanitaria de la leche y los productos lácteos, Manual de prácticas. Disponible en:https://www.uaa.mx/centros/cca/MVZ/ M/9/ManualdepracticasC4.pdf.
[3] D.S. N007-2017-MINAGRI : Reglamento de la Leche y Productos Lácteos.

[4] A. Abril y V. Pillco, Tesis de Licenciatura, Universidad de Cuenca-Ecuador, 2013.

[5] J. Miller, Bioquímica de Proteínas (COPIBOOK. S.L, Madrid, 2016), 4 ed., p.

E-mails: karlamejia.futamante@gmail.com 